Check for updates

Cite this: RSC Adv., 2017, 7, 51264

\title{
Direct cryopreservation of adherent cells on an elastic nanofiber sheet featuring a low glass- transition temperature
}

\begin{abstract}
Onon Batnyam, ${ }^{a}$ Shin-ichiro Suye ${ }^{\mathrm{ab}}$ and Satoshi Fujita (iD *ab
Cryopreservation of ready-made cell-biomaterial composites is an essential aspect of modern regenerative medicine and tissue engineering. However, in the freeze-thawing of adherent cells, a problem encountered is the detachment of cells due to the intracellular tensile stress caused by dehydration. To reduce the cell detachment, a scaffold that retains elasticity at freezing temperatures was investigated here for use in direct cryopreservation of adherent cells. We focused on electrospun polyurethane (PU) nanofiber sheets, which featured a lower glass-transition temperature than the freezing temperature used and presented a loose mesh-like structure of nanofibers. Consequently, the recovery of cells cultured on the PU nanofiber sheets and then freeze-thawed was higher than the recovery of cells cultured on polystyrene films and fibers. Furthermore, higher cell recovery was obtained with randomly oriented PU nanofibers than with highly aligned PU nanofibers. These results suggest that the elasticity of the polymer and the looseness of the fiber mesh are key factors that enhance the recovery of adherent cells after freeze-thawing. This is the first report demonstrating that the elastic nanofiber scaffold is an available material that enables the cryopreservation of adherent cells; the use of this scaffold could substantially improve the cryopreservation outcome of cell-biomaterial composites.
\end{abstract}

Received 25th September 2017
Accepted 29th October 2017

DOI: 10.1039/c7ra10604a

rsc.li/rsc-advances presence of dimethyl sulfoxide (DMSO) without the formation of intracellular ice crystals. ${ }^{8}$ Some of DMSO-free cryoprotectant solutions were also commercialized for slow freezing, such as CryoSOfree $^{\mathrm{TM}}$ (Sigma-Aldrich, USA), CryoScarless ${ }^{\circledR}$ (BioVerde, Japan), and Stem-Cellbanker® (Zenoaq, Japan). However, even with slow freezing, the cryopreservation of adherent cells is considerably more challenging than that of single-cell suspensions; this is because of the shrinkage and deformation of cells caused by the exclusion of water, ${ }^{9}$ which results in the detachment and breakage of cells. To overcome these hurdles and successfully cryopreserve adherent cells, several approaches have been reported, including enhancement of cell-substrate interaction, ${ }^{10,11}$ supportive use of hydrogels, ${ }^{12-14}$ augmentation of cell-cell interaction, ${ }^{15}$ and improvement of freezing conditions. ${ }^{16,17}$ Notably, the use of high concentrations of the cryoprotectant DMSO, which enhances the dehydration effect and inhibits of icecrystal formation, was reported to allow direct cryopreservation of adherent cells cultured on polydimethylsiloxane substrate. ${ }^{\mathbf{1 8}}$ However, the development of a systematic approach for the cryopreservation of adherent cells remains under investigation.

The attachment of cells to any substrate requires the recruitment of the transmembrane receptor integrin and the formation of focal adhesions, where cells sense and adapt themselves to their microenvironment, ${ }^{19}$ and the maintenance of cell adhesion after the freeze-thawing process is critical for cell viability and function. However, during the freeze-thawing process, cells adhered onto a stiff substrate detach and break 
due to the differential thermal contraction of the cells and the substrate. ${ }^{20}$ Therefore, we focused here on the elasticity of the scaffold for maintaining tight adhesion with cells after freezethawing. We hypothesized that a substrate that retains its elasticity at a freezing temperature would inhibit the exfoliation of adherent cells from the surface that results from the contraction caused by the dehydration occurring in a slowfreezing procedure. To test this possibility, we designed a substrate based on considering two viewpoints: first, we focused on an electrospun nanofiber sheet as an elastic scaffold; this nanofiber sheet, which is one of the promising forms of scaffolds suitable for cell-biomaterial composites, mimics the natural structure of the extracellular matrix and thus controls cell proliferation, migration, and differentiation. ${ }^{21-24}$ The loose mesh-like structure of an electrospun nanofiber sheet would mitigate the detachment and breakage of adherent cells even if the cells deform and shrink. Second, we focused on a polymer featuring a glass-transition temperature $\left(T_{\mathrm{g}}\right)$ that is lower than the freezing temperature. Here, we selected polyurethane, the $T_{\mathrm{g}}$ of which is $-40{ }^{\circ} \mathrm{C} .{ }^{25}$ Thus, for the cryopreservation of adherent cells, we investigated the suitability of a scaffold that retains its elasticity at freeze-thawing temperatures.

\section{Experimental}

\section{Materials}

The following materials were from commercial sources: thermoplastic polyether-polyurethane-elastomer (PU; $M_{\mathrm{w}} 146000$, Elastollan $\AA$ 1180A10), BASF (Ludwigshafen, Germany); polystyrene (PS; $M_{\mathrm{w}} 350$ 000), Sigma-Aldrich (St. Louis, MO, USA); and tetrahydrofuran (THF), N,N-dimethylformamide (DMF), and DMSO, Wako Pure Chemical Industries (Osaka, Japan). All other chemicals and reagents were of analytical grade and were used without further purification.

\section{Fabrication of substrates}

PU and PS films. PU and PS films featuring a smooth surface were prepared from $2 \%$ and $4.8 \%(\mathrm{w} / \mathrm{v})$ PU and PS solutions in THF, respectively, by using a casting method. Briefly, the polymer solutions were poured on a smooth glass surface and ultrasonicated for $30 \mathrm{~s}$ to remove all air bubbles from the solutions, and the solutions were then vacuum-dried using an aspirator (ASP-13, Iwaki Glass, Tokyo, Japan) for $2 \mathrm{~h}$ and stored in a desiccator for 1 week; completely dried films were fixed on acrylic frames (Scheme 1A). The sterilization of obtained films and the enhancement of their surface hydrophilicity were performed through oxygen-plasma treatment $(40 \mathrm{kHz}, 100 \mathrm{~W}, 30 \mathrm{~s}, 0.1 \mathrm{MPa})$ using a plasma reactor (Femto, Diener Electronics, Ebhausen, Germany; chamber size: diameter $\times$ depth, $95 \times 270 \mathrm{~mm}$ ).

Electrospun fiber scaffolds. Electrospinning solutions were prepared as follows: $11 \%(\mathrm{w} / \mathrm{v})$ PU and $25 \%(\mathrm{w} / \mathrm{v})$ PS were dissolved in THF and DMF : THF at 1:9 ratio, respectively, and gently mixed overnight on a rotator (BC-710, BIO-CRAFT, Tokyo, Japan) at room temperature. PU and PS fiber scaffolds were electrospun on acrylic frames (Scheme 1A) by using a commercial electrospinning setup (NANON, MECC, Fukuoka, Japan), which consisted of a 23 G-needle nozzle, a syringe pump, a highvoltage power supply, and a rotating collector in a closed chamber. The electrospinning conditions were the following: applied electric field: $1.67 \mathrm{kV} \mathrm{cm}{ }^{-1}$; infusion flow rate: $0.6 \mathrm{~mL} \mathrm{~h}^{-1}$; collector rotation speed: $1500 \mathrm{rpm}$ (linear velocity $\left.15 \mathrm{~m} \mathrm{~s}^{-1}\right)$ for aligned fibers and $50 \mathrm{rpm}\left(0.5 \mathrm{~m} \mathrm{~s}^{-1}\right)$ for random fibers. Sterilization and surface-hydrophilicity enhancement of nanofibrous scaffolds were once again achieved through oxygen-plasma treatment (as mentioned above).

\section{Characterization of fabricated substrates}

Morphological characterization by scanning electron microscopy (SEM). The morphology of PU and PS substrates was examined by performing scanning electron microscopy (SEM; S$2600 \mathrm{H}$, Hitachi, Tokyo, Japan) at an accelerating voltage of $15 \mathrm{kV}$. The thickness of PU and PS films was measured from the cross-sections of the films, which were prepared by cutting the samples in liquid nitrogen. The films and the electrospun fiber scaffolds were sputtered with $\mathrm{Pt} / \mathrm{Pd}$ by using an ion sputter (E-1030, Hitachi) for $120 \mathrm{~s}$ before observation. The diameter and orientation of the fibers composing the PU and PS scaffolds were examined from 10 randomly selected areas of the scaffolds by using Fiji software (fiji.sc; ImageJ, NIH, USA). Briefly, a power spectrum was obtained through Fourier transformation of the SEM images of fibers, and the second-order parameter, $S$, was calculated from the distribution of the intensity of the power spectrum as a function of angles:

$$
S=\left\langle 3 \cos ^{2} \theta-1\right\rangle / 2
$$

where $\theta$ is a difference from the entire orientation and \langle\rangle represents the averaged value..$^{26,27}$
(A)

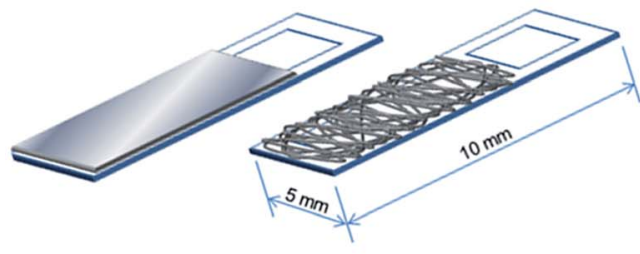

(B)

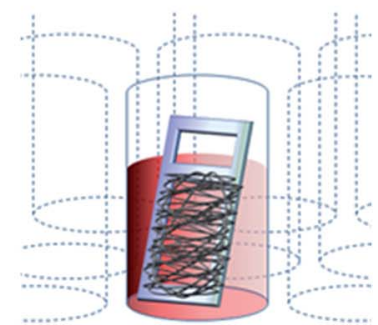

Scheme 1 (A) Design of film and fibrous scaffolds on acrylic substrates. (B) Cryopreservation of cells cultured on a fibrous scaffold in a cryotube. 
Dynamic mechanical analysis (DMA). DMA was performed on PU and PS films $(25 \times 5 \mathrm{~mm})$, using a dynamic viscoelasticity apparatus (Rheogel-E4000, UBM, Kyoto, Japan) at $1 \mathrm{~Hz}$ and a heating rate of $2{ }^{\circ} \mathrm{C} \min ^{-1}$ from $-120{ }^{\circ} \mathrm{C}$ to $200{ }^{\circ} \mathrm{C}$, to measure the dynamic mechanical spectra, storage modulus $E^{\prime}$, loss modulus $E^{\prime \prime}$, and mechanical damping $\tan \delta$.

\section{Cryopreservation of myoblast cells}

Cell culture. Mouse C2C12 myoblasts were seeded onto scaffolds fixed on the bottom of $\phi 35 \mathrm{~mm}$ culture dishes at the density of $2.5 \times 10^{4}$ cells per $\mathrm{cm}^{2}$ and maintained in Minimum Essential Medium (GIBCO, Thermo Fisher Scientific, Waltham, MA, USA) supplemented with $10 \%$ fetal bovine serum (BIOWEST, Nuaillé, France), $100 \mathrm{U} \mathrm{mL}^{-1}$ penicillin, and $100 \mu \mathrm{g} \mathrm{mL}^{-1}$ streptomycin (Invitrogen). Cells were incubated at $37{ }^{\circ} \mathrm{C}$ under $5 \% \mathrm{CO}_{2}$ in a humidified atmosphere.

Slow freezing and rapid thawing of adherent cells. For freezing the cultured adherent cells, a sample was first transferred into a $1.8 \mathrm{~mL}$ cryotube (Thermo Fisher Scientific) holding with $500 \mu \mathrm{L}$ of complete culture medium containing $10 \%$ DMSO. The cryotube was placed inside a freezing vessel (Bicell, Nihon Freezer, Tokyo, Japan), which provided the required cooling rate of $1{ }^{\circ} \mathrm{C} \min ^{-1},{ }^{28}$ and then transferred to a $-80{ }^{\circ} \mathrm{C}$ freezer (Scheme 1B) and maintained at $-80{ }^{\circ} \mathrm{C}$ overnight. Frozen samples were thawed as rapidly as possible by transferring them directly from the $-80{ }^{\circ} \mathrm{C}$ vessel to a $37^{\circ} \mathrm{C}$ dry-bath incubator (Ultimate, Major Science, Saratoga, CA, USA).

SEM observation of cultured cells. Cells cultured on scaffolds were fixed with 4\% paraformaldehyde in PBS for $15 \mathrm{~min}$ and then dehydrated by sequentially immersing them in serially diluted ethanol solutions (\% (v/v): 30, 50, 60, 70, 80, 90, 95, and 99.5) and $t$-butyl alcohol 4 times for $10 \mathrm{~min}$ each. The samples were freezedried overnight using a freeze-dryer (FDU-830, EYELA, Tokyo, Japan) and then sputter-coated with Pt/Pd. SEM observation was performed using an S-2600 $\mathrm{H}$ microscope (as mentioned above).
Metabolic activity measurement. The metabolic activity of cells was analyzed immediately after thawing or at $24 \mathrm{~h}$ after thawing by using a colorimetric assay kit (Cell Count Reagent SF, Nacalai Tesque, Kyoto, Japan). To measure the activity immediately after thawing, each sample was transferred into a well of a 96-well plate holding with $200 \mu \mathrm{L}$ of culture medium and $20 \mu \mathrm{L}$ of SF reagent were added. After incubation for $2 \mathrm{~h}$ at $37{ }^{\circ} \mathrm{C}, 100 \mu \mathrm{L}$ of the medium from each well was collected and the absorbance at $450 \mathrm{~nm}$ was measured using a microplate spectrophotometer (Multiskan GO, Thermo Fisher Scientific). The metabolic activity of cells at $24 \mathrm{~h}$ after thawing was measured by using the same method after the thawed samples had been incubated in a new culture dish with culture medium at $37{ }^{\circ} \mathrm{C}$ under $5 \% \mathrm{CO}_{2}$ in a humidified atmosphere.

\section{Statistical analysis}

All experiments were conducted at least thrice, and all values are reported as means \pm standard deviation (SD). For statistical analysis, nonparametric Kruskal-Wallis tests were performed using $\mathrm{R}$ (Version 2.1.7); $p<0.05$ was considered statistically significant.

\section{Results}

\section{Direct cryopreservation on films}

Characterization of PS and PU films. To improve the recovery of adherent cells by reducing mechanical damage during the freeze-thawing process, we selected PU as a scaffold material, because PU is softer and more flexible than PS, the material used in conventional culture dishes. PS film and PU film were fabricated using a casting method and cut into the desired shape and size for use in further analyses. SEM examination of the obtained films revealed a smooth surface with few defects (Fig. 1). The fabricated PS and PU films showed an average thickness of $51.0 \pm 2.5$ and $57.8 \pm 0.5 \mu \mathrm{m}$, respectively. To
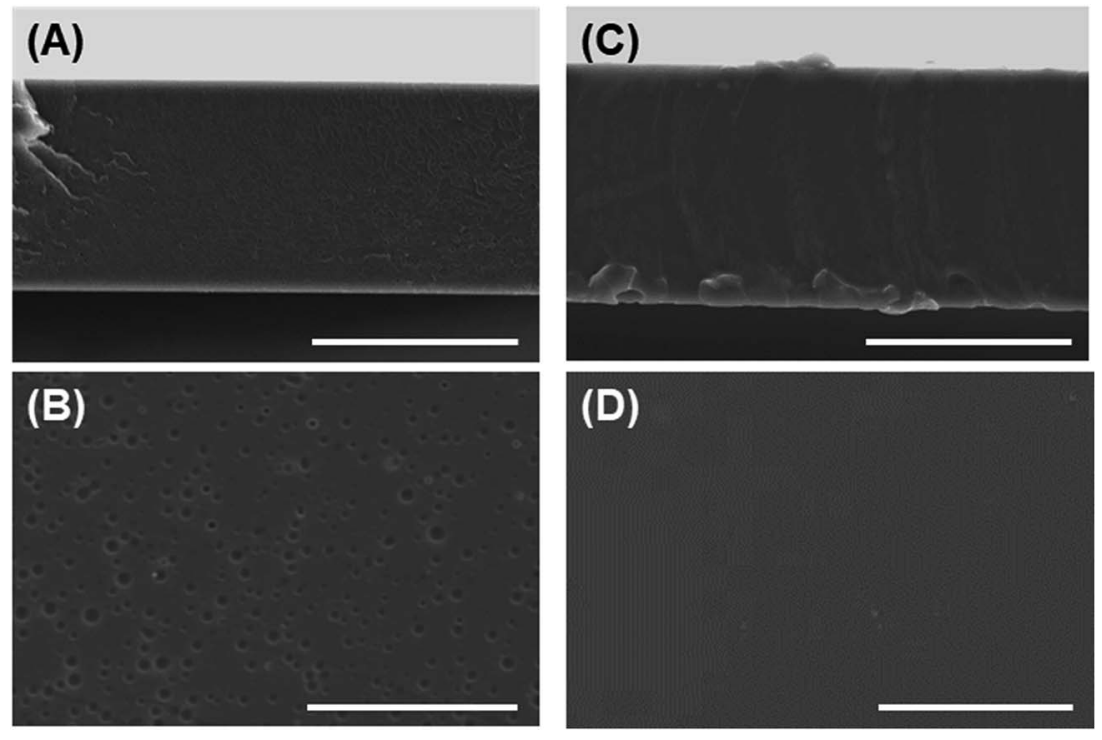

Fig. 1 Morphological observation of fabricated films. (A, B) PS film, (C, D) PU film; (A, C) cross-sectional views, (B, D) top views. Bars = $50 \mu$ m. 
(A)

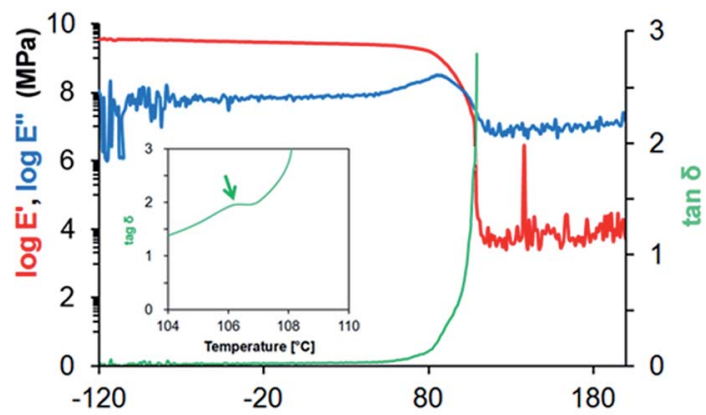

(B)

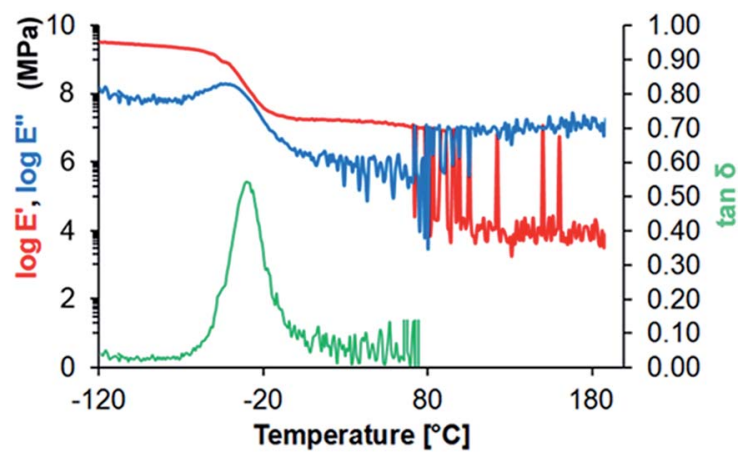

Fig. 2 DMA analysis of fabricated films. (A) PS film, (B) PU film. Storage modulus $E^{\prime}$ (red, left axis), loss modulus $E^{\prime \prime}$ (blue, left axis), and mechanical damping $\tan \delta$ (green, right axis) are represented. Inset, magnified graph of $\tan \delta$, showing the peak of $T_{\mathrm{g}}$.

investigate the stiffness of these materials at the freeze-thawing temperatures, we performed DMA to measure the viscoelastic properties of PS and PU films presenting a smooth surface
(Fig. 2): whereas PS films featured a peak at $106{ }^{\circ} \mathrm{C}$ in $\tan \delta$, which corresponds to its glass-transition temperature $\left(T_{\mathrm{g}}\right), \mathrm{PU}$ films showed a peak at $-30^{\circ} \mathrm{C}$ in $\tan \delta$, which reflects the microBrownian segmental motion of amorphous PU at a freezing temperature.

Post-thaw recovery of cells seeded onto PU and PS films. We next examined the adhesion-dependent survival of cells after thawing. We have used C2C12 myoblasts for a model experiment to investigate a potential clinical application of the scaffold for cryopreservation of mesenchymal cells. Cells were seeded onto fabricated films cast on glass and then frozen slowly to $-80{ }^{\circ} \mathrm{C}$, and the metabolic activity of the cells was measured immediately after thawing and after $24 \mathrm{~h}$ incubation in complete medium at $37^{\circ} \mathrm{C}$. Post-thaw recovery of cells was then calculated as the ratio of the metabolic activity before and immediately after freeze-thawing, and the post-thaw foldincrease in cells was calculated as the ratio of the metabolic activity immediately after freeze-thawing and after the $24 \mathrm{~h}$ incubation. Cells seeded on smooth PS and PU films adhered on the surface tightly and extended before freeze-thawing (Fig. 3A and B). Immediately after freeze-thawing, cell survival on PS and PU was $38.7 \%$ and $40.0 \%$, respectively (Fig. $3 \mathrm{C}$ ), and the fold-increase in cells after the $24 \mathrm{~h}$ incubation was 2.17 and 1.80 , respectively (Fig. 3D). No significant difference in cell survival or recovery after freeze-thawing was measured with either PS or PU film.

\section{Direct cryopreservation on nanofiber sheets}

Characterization of PU and PS nanofiber sheets. To obtain PU and PS substrates exhibiting high elasticity, which helps
(A)

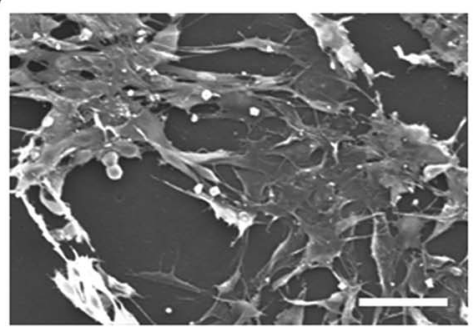

(C)

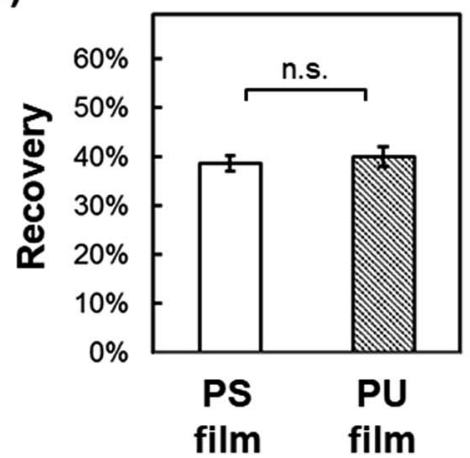

(B)

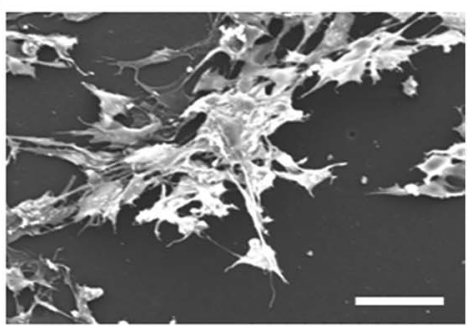

(D)

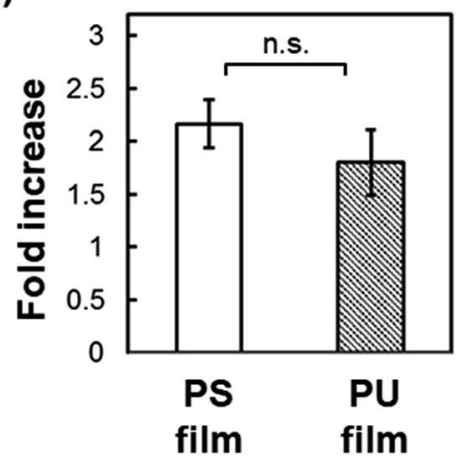

Fig. 3 Cryopreservation on cast film. (A, B) SEM images before cryopreservation of cells cultured on PS film (A) and PU film (B). Bars $=50 \mu m$. (C) Post-thaw recovery of cells cultured on PS and PU films. (D) Fold-increase in cells after $24 \mathrm{~h}$ culture of post-thaw cells. Means \pm SD, $n=3$; n.s., no significant difference $(p>0.05)$. 

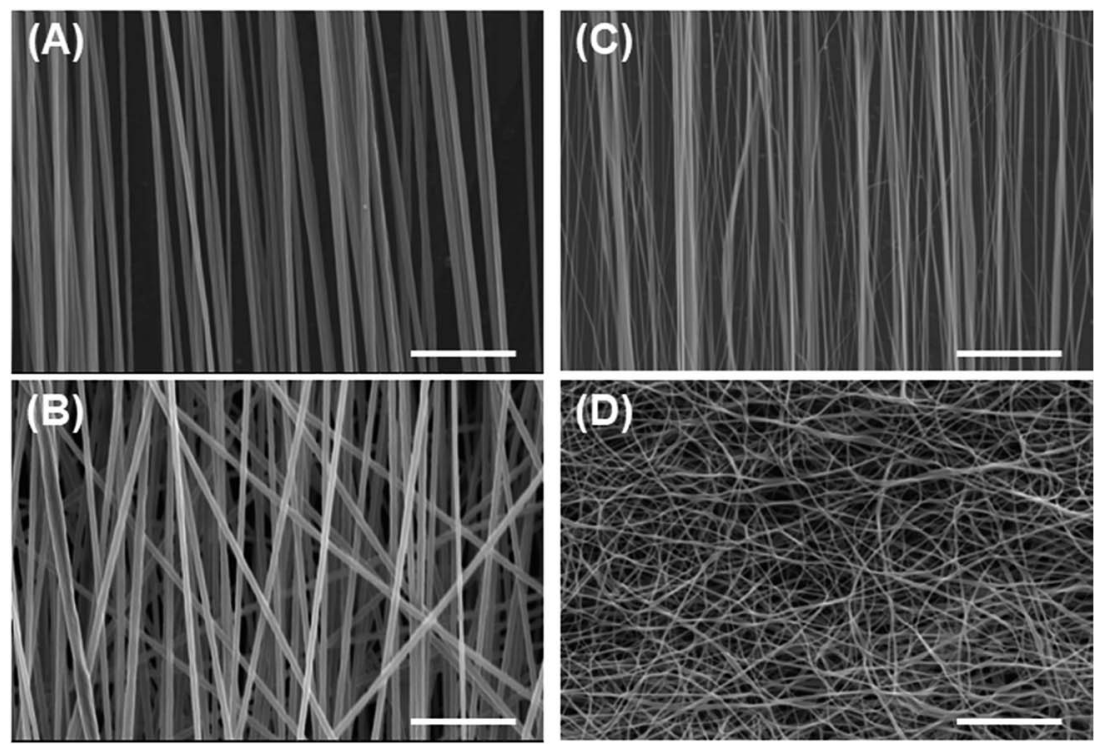

Fig. 4 SEM images of PU electrospun fibers. (A) Highly aligned PS fibers, (B) less-aligned PS fibers, (C) aligned PU fibers, and (D) randomly oriented PU fibers. Bars $=50 \mu \mathrm{m}$.

reduce cell damage caused by differential thermal contraction between the substrate and the cells during the freeze-thawing process, we fabricated electrospun PU and PS fiber sheets. We also expected cell attachment to be increased with these sheets. The orientation of the nanofibers was controlled by the rotation speed of the electrospinning collector: a rotation speed of $1500 \mathrm{rpm}$ resulted in aligned fibers, whereas a low rotation speed of $50 \mathrm{rpm}$ resulted in less aligned or randomly oriented fibers. SEM examination of the fibers (Fig. 4) revealed that highly aligned and less-aligned PS fibers featured a diameter of $3.52 \pm 1.62$ and $3.47 \pm 0.46 \mu \mathrm{m}$ and a second order parameter $S$ of 0.89 and 0.85 , respectively, where $S$ values close to 1 and 0 indicate perfectly aligned fibers and randomly oriented fibers, respectively. Even with a reduction in the speed of the collector, PS fibers exhibiting a higher random alignment could not be obtained due to the stiffness of the PS fibers. In the case of the aligned and random PU fibers obtained, the diameter was 0.52 \pm 0.19 and $1.07 \pm 0.20 \mu \mathrm{m}$, and $\mathrm{S}$ was 0.91 and 0.43 , respectively.
Post-thaw recovery of cells seeded onto PU and PS nanofiber sheets. We hypothesized that in the cryopreservation of cells, the damage caused to adherent cells by shrinkage during freeze-thawing would be reduced with the use of fibrous scaffolds exhibiting elasticity and looseness. To test this, cells were seeded onto fibrous scaffolds and subject to freeze-thawing (Fig. 5) as in previous experiments. The viability of cells seeded onto highly aligned and less-aligned PS fibrous sheets was $39.8 \% \pm 2.1 \%$ and $43.4 \% \pm 3.0 \%$, respectively, and after $24 \mathrm{~h}$ culture on these two sheets, the fold-increase in cells was $1.83 \pm$ 0.15 and $1.60 \pm 0.15$, respectively. By comparison, the viability of cells seeded onto aligned and random PU fibrous substrates was higher, $48.8 \% \pm 1.7 \%$ and $54.9 \% \pm 4.3 \%$, respectively; the fold-increase in cells after $24 \mathrm{~h}$ incubation on these sheets was $1.84 \pm 0.21$ and $1.57 \pm 0.10$, respectively. The cells seeded onto a random PU fiber sheet adhered on the surface tightly and extended before and after freeze-thawing, and a loosened mesh structure of fibers was observed after freeze-thawing (Fig. 6). The rest of cells not recovering showed the detachment.
(A)

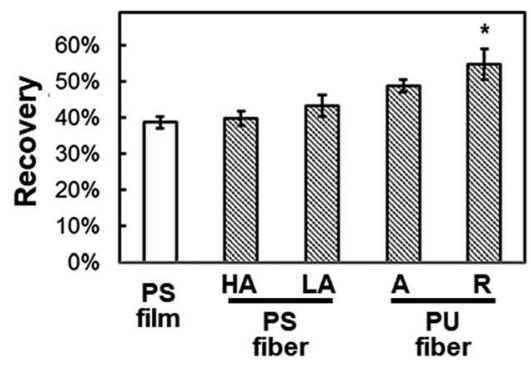

(B)

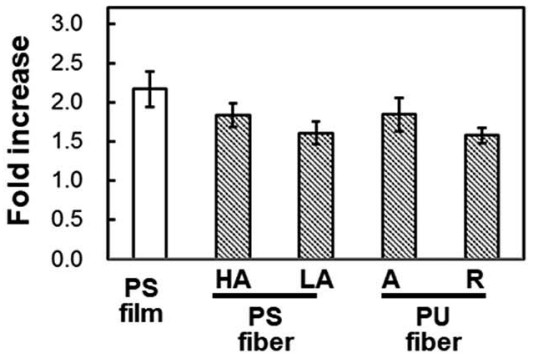

Fig. 5 Direct cryopreservation of cells cultured on fiber scaffolds. (A) Post-thaw recovery of cells. (B) Fold-increase in cells after $24 \mathrm{~h}$ culture of post-thaw cells. HA: highly aligned PS fibers; LA: less-aligned PS fibers; A: aligned PU fibers; R: randomly oriented PU fibers. PS film was used as a control. Means $\pm \mathrm{SE}, n=3$; ${ }^{*} p<0.05$, compared with PS film. 
(A)

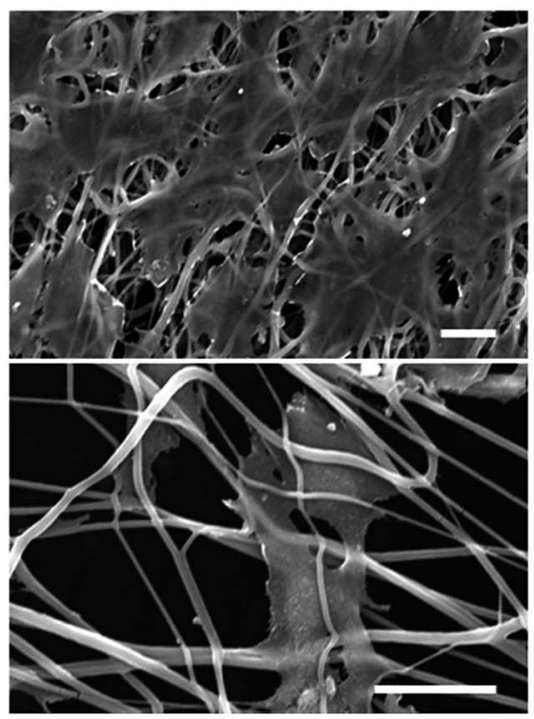

(B)

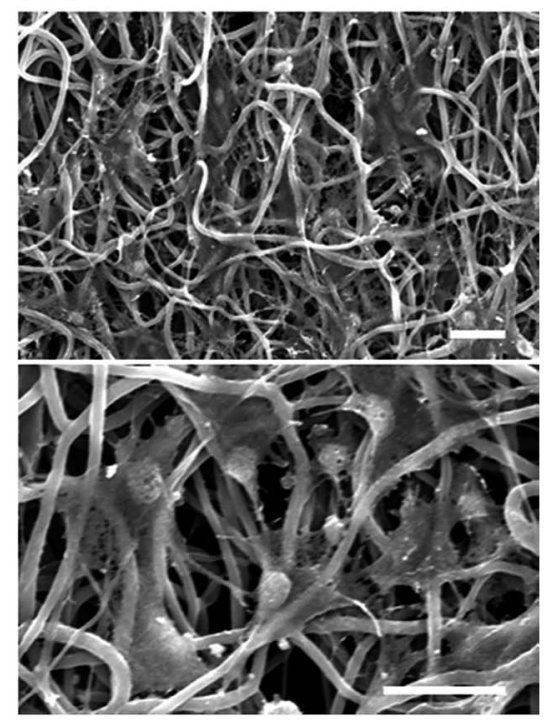

Fig. 6 SEM images of cells cultured on random PU fibers. (A) Cells before freezing. (B) Cells immediately after direct freeze-thawing on scaffolds. Bars $=20 \mu \mathrm{m}$.

\section{Discussion}

\section{Effect of polymer elasticity}

In this study, we tested whether a polymer scaffold that exhibits elasticity at the freezing temperature would enable cells to maintain their adhesion even if the adherent cells contract because of dehydration during the freezing process, and thus

(A) Effect of fiber elasticity

(B) Effect of looseness of fiber mesh

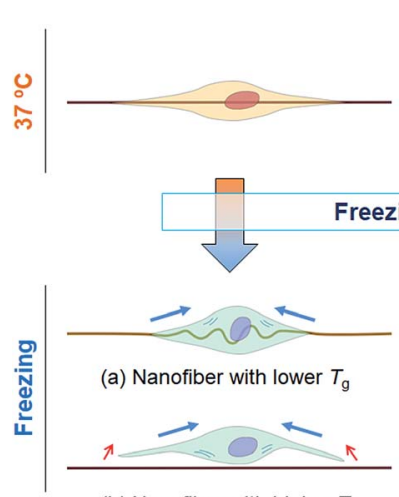

(b) Nanofiber with higher $T_{\mathrm{g}}$

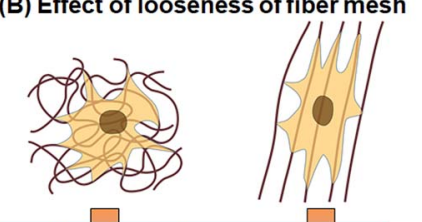

reezing with dehydration
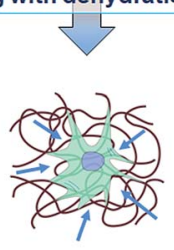

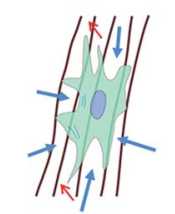

(d) Aligned nanofiber (c) Random nanofiber

Scheme 2 Schematic illustration of cell damage in cryopreservation. During the freezing process, a cell experiences a contraction force generated by the shrinkage caused by dehydration (blue arrows). If the deformation of the cell is less than that of the scaffold, cell detachment is induced (red arrows). (A) Effect of fiber elasticity. (a) Cells extending along a nanofiber featuring a low $T_{\mathrm{g}}$ can shrink and still maintain their adhesion to the fiber due to the elasticity of fiber. (b) Cells extending on a stiff nanofiber featuring a high $T_{\mathrm{g}}$ would detach because of the contraction force. (B) Effect of looseness of the fiber mesh structure. (c) Cells cultured on a randomly oriented nanofiber sheet can shrink and still retain their adhesion to the sheet due to the looseness of the fiber mesh. (d) Cells cultured on aligned nanofibers can be readily detached along the fiber direction.

increase the viability of freeze-thawed adherent cells. The elasticity of a polymer at the freezing temperature depends on its $T_{\mathrm{g}}$. If the polymer $T_{\mathrm{g}}$ is lower than the melting temperature of a medium containing $10 \%$ DMSO, approximately $-20{ }^{\circ} \mathrm{C},{ }^{29}$ the polymer can deform by creeping during the freezing process (Scheme 2A). To investigate whether a polymer featuring a low $T_{\mathrm{g}}$ can be used for developing an effective cryopreservation scaffold, we compared the recovery of cells cultured on PS and PU scaffolds, fabricated in the form of films and fibers, after direct freeze-thawing of the cells on the scaffolds. We found that whereas $60 \%$ of the cells cultured on both films and on the PS fiber exfoliated after freeze-thawing, cell recovery was high with the PU fiber. We can attribute these results to the stiffness of the scaffold: at the melting temperature of the medium, PS was in a stiff glassy state, but PU was in a rubbery state. The elasticity of the PU used in this study was approximately $8 \mathrm{MPa}$ at $-10{ }^{\circ} \mathrm{C}$, as determined through DMA measurement, and SEM analysis revealed that the diameter of each PU fiber was roughly $1 \mu \mathrm{m}$. Therefore, a force of $6 \times 10^{6} \mathrm{pN}$ would be required to bend a single PU fiber. Dembo and Wang reported that the

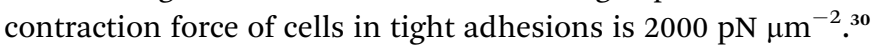
When cells extend to $5000 \mu \mathrm{m}^{2}$, the force required to detach the cells from the substrate is $10 \times 10^{6} \mathrm{pN}$, which is larger than the force necessary to bend the fiber.

\section{Effect of geometry of fiber mesh}

We also investigated the effect of the fiber mesh structure on cell recovery: the recovery was low with highly oriented fibers, which indicated that the tight and tensioned mesh structure caused cell detachment, particularly in the direction of fiber alignment; by contrast, random PU fibers exhibited a looseness in their mesh structure in the fiber sheets, which resulted in the maintenance of cell adhesions (Scheme 2B). Here, the loosenes 
was indexed by the randomness of fiber geometry, $S$. Moreover, the diameter and the pore sizes of the fibers were very small relative to the dimension of cells, and thus the cells attached to the substrate at multiple focal-adhesion sites. SEM analysis revealed that these multiple adhesions were retained after the freeze-thawing process, and this resulted in the high cell recovery observed with random PU fibers.

Intriguingly, cell proliferation after culture for $24 \mathrm{~h}$ on aligned PU fibers was higher than that after culture on random PU nanofibers. Cells have been previously reported to be sensitive to the topographical arrangement of the substrate. Cell stretching can induce the accumulation of vinculin at talin-containing focal adhesions by exposing vinculin-binding sites in the talin rod domain, and can thereby allow the reinforcement of the focal adhesions with vinculin. ${ }^{31}$ The extension of cells triggers the development of strong adhesion and pronounced stress fibers. $^{32-35}$ Furthermore, several studies have provided evidence that cells prefer random arrangements, which can regulate cellular functions such as attachment, proliferation, and survival, over perfect grooves, pits, and pillars. ${ }^{36-38}$ Thus, random geometry is favorable for mitigating the tension that arises during freezethawing, whereas high orientation is preferable for cell proliferation after thawing. Overall, these findings suggest the requirement of an optimal geometry of the fiber mesh structure, which should be further investigated to maximize the yield of cells after freeze-thawing and culturing the cells.

\section{Conclusions}

To meet the increasing demand for tissue allografts, the development of artificial tissue-engineering constructs has been widely investigated; however, the maintenance of the shelf-life and post-thaw biofunctionality of the constructs is a challenge that remains poorly addressed. Here, we first found that nanofiber materials, which present a loose mesh structure and exhibit elasticity at freezing temperatures due to the use of polymers featuring a low $T_{\mathrm{g}}$, can be used for direct cryopreservation of adherent cells. Our study can potentially contribute to the commercial application and transportation of therapeutic cells for regenerative medicine by providing a standard procedure for the cryopreservation of adherent cells, and the study should also facilitate the further development of this research field. We expect that our strategy is also applicable to other emerging cryoprotectants for slow freezing from the proposed mechanism of cryoprotection. Moreover, the results of cellculture assays indicated that highly efficient cryoprotectant materials can be developed by modifying the surface cell adhesion.

\section{Conflicts of interest}

There are no conflicts to declare.

\section{Acknowledgements}

This work was financially supported by JSPS KAKENHI Grant Number 16K05908.

\section{References}

1 R. H. Harrison, J. P. St-Pierre and M. M. Stevens, Tissue Eng., Part B, 2014, 20, 1-16.

2 G. J. Morris and E. Acton, Cryobiology, 2013, 66, 85-92.

3 D. Balci and A. Can, Curr. Stem Cell Res. Ther., 2013, 8, 60-72.

4 T. Miyazaki and H. Suemori, Methods Mol. Biol., 2015, 1235, 97-104.

5 C. J. Hunt, Transfus. Med. Hemother., 2011, 38, 107-123.

6 A. Cobo and C. Diaz, Fertil. Steril., 2011, 96, 277-285.

7 L. L. Kuleshova, S. S. Gouk and D. W. Hutmacher, Biomaterials, 2007, 28, 1585-1596.

8 J. O. Karlsson, E. G. Cravalho, I. H. Borel Rinkes, R. G. Tompkins, M. L. Yarmush and M. Toner, Biophys. J., 1993, 65, 2524-2536.

9 P. Mazur, Am. J. Physiol.: Cell Physiol., 1984, 247, C125-C142.

10 L. Ji, J. J. de Pablo and S. P. Palecek, Biotechnol. Bioeng., 2004, 88, 299-312.

11 X. Xu, Y. Liu and Z. F. Cui, J. Tissue Eng. Regener. Med., 2014, 8, 664-672.

12 R. Malpique, F. Ehrhart, A. Katsen-Globa, H. Zimmermann and P. M. Alves, Tissue Eng., Part C, 2009, 15, 373-386.

13 A. Katsen-Globa, I. Meiser, Y. A. Petrenko, R. V. Ivanov, V. I. Lozinsky, H. Zimmermann and A. Y. Petrenko, J. Mater. Sci.: Mater. Med., 2014, 25, 857-871.

14 H. F. Ahmad and A. Sambanis, Acta Biomater., 2013, 9, 68146822.

15 J. P. Acker, A. Larese, H. Yang, A. Petrenko and L. E. McGann, Cryobiology, 1999, 38, 363-371.

16 T. L. Bailey, M. Wang, J. Solocinski, B. P. Nathan, N. Chakraborty and M. A. Menze, Cryobiology, 2015, 71, 472-480.

17 X. Xu, Y. Liu, Z. Cui, Y. Wei and L. Zhang, J. Biotechnol., 2012, 162, 224-231.

18 Y. Nagahara, H. Sekine, M. Otaki, M. Hayashi and N. Murase, Cryobiology, 2016, 72, 53-59.

19 J. D. Humphrey, E. R. Dufresne and M. A. Schwartz, Nat. Rev. Mol. Cell Biol., 2014, 15, 802-812.

20 B. L. Liu, J. McGrath, L. McCabe and M. Baumann, Afr. J. Biotechnol., 2006, 5, 2014-2019.

21 C. Huang and R. Ogawa, FASEB J., 2010, 24, 3625-3632.

22 J. Holst, S. Watson, M. S. Lord, S. S. Eamegdool, D. V. Bax, L. B. Nivison-Smith, A. Kondyurin, L. Ma, A. F. Oberhauser, A. S. Weiss and J. E. Rasko, Nat. Biotechnol., 2010, 28, 1123-1128.

23 S. Fujita, H. Shimizu and S. Suye, J. Nanotechnol., 2012, 2012, 429890.

24 O. Batnyam, H. Shimizu, K. Saito, T. Ishida, S. Suye and S. Fujita, RSC Adv., 2015, 5, 80357-80364.

25 V. Pistor, D. de Conto, F. G. Ornaghi and A. J. Zattera, J. Nanomater., 2012, 2012, 283031.

26 R. S. Stein and F. H. Norris, J. Polym. Sci., Part A: Polym. Chem., 1956, 21, 381-396.

27 S. Nomura, H. Kawai, I. Kimura and M. Kagiyama, J. Polym. Sci., Part B: Polym. Phys., 1970, 8, 383-400.

28 S. Kurita, US. Pat., US5105627 A, 1992. 
29 T. M. Gurina, A. V. Pakhomov, A. L. Polyakova, E. I. Legach and G. A. Bozhok, Cell Tissue Banking, 2016, 17, 303-316.

30 M. Dembo and Y. L. Wang, Biophys. J., 1999, 76, 2307-2316.

31 H. Hirata, H. Tatsumi, C. T. Lim and M. Sokabe, Am. J. Physiol.: Cell Physiol., 2014, 306, C607-C620.

32 S. Pellegrin and H. Mellor, J. Cell Sci., 2007, 120, 3491-3499.

33 E. G. Rens and R. M. H. Merks, Biophys. J., 2017, 112, 755766.

34 C. H. Seo, H. Jeong, Y. Feng, K. Montagne, T. Ushida, Y. Suzuki and K. S. Furukawa, Biomaterials, 2014, 35, 22452252.
35 S. Y. Tee, J. Fu, C. S. Chen and P. A. Janmey, Biophys. J., 2011, 100, L25-L27.

36 D. J. Kyle, A. Oikonomou, E. Hill and A. Bayat, Biomaterials, 2015, 52, 88-102.

37 E. A. Cavalcanti-Adam, T. Volberg, A. Micoulet, H. Kessler, B. Geiger and J. P. Spatz, Biophys. J., 2007, 92, 2964-2974.

38 J. Huang, S. V. Grater, F. Corbellini, S. Rinck, E. Bock, R. Kemkemer, H. Kessler, J. Ding and J. P. Spatz, Nano Lett., 2009, 9, 1111-1116. 